\title{
Visualization of Laterally Spreading Colorectal Tumors by Using Image-Enhanced Endoscopy
}

\author{
Naoto Tamai, ${ }^{1}$ Yutaka Saito, ${ }^{1}$ Taku Sakamoto, ${ }^{1}$ Takeshi Nakajima, ${ }^{1}$ Takahisa Matsuda, ${ }^{1}$ \\ Namasivayam Vikneswaran, ${ }^{2}$ and Hisao Tajiri ${ }^{3}$
}

\footnotetext{
${ }^{1}$ Endoscopy Division, National Cancer Center Hospital, 5-1-1 Tsukiji, Chuo-ku, Tokyo 104-0045, Japan

${ }^{2}$ MBBS, Department of Gastroenterology and Hepatology, Singapore General Hospital, Singapore 769608

${ }^{3}$ Department of Gastroenterology and Hepatology, The Jikei University School of Medicine,

3-25-8 Nishi Shinbashi, Minato-ku, Tokyo 105-8461, Japan
}

Correspondence should be addressed to Yutaka Saito, ytsaito@ncc.go.jp

Received 20 September 2011; Accepted 15 October 2011

Academic Editor: Cesare Hassan

Copyright (๑) 2012 Naoto Tamai et al. This is an open access article distributed under the Creative Commons Attribution License, which permits unrestricted use, distribution, and reproduction in any medium, provided the original work is properly cited.

\begin{abstract}
Laterally spreading tumors may sometimes evade detection by colonoscopy. This study aimed to evaluate the use of imageenhanced endoscopy for visualizing laterally spreading tumors of the nongranular type. We reviewed consecutive patients with 47 non-granular-type laterally spreading tumors that had been examined using white-light imaging, autofluorescence imaging, narrow-band imaging, and chromoendoscopy with indigo carmine. The quality of visualization was evaluated using a 5-point scale by less- and more-experienced endoscopists. Autofluorescence imaging provided significantly better visualization than whitelight imaging for both less-experienced and experienced endoscopists. On the other hand, no significant differences were observed between the quality of visualization provided by white-light imaging and narrow-band imaging for less-experienced endoscopists. Autofluorescence imaging provides high-quality visualization of non-granular-type laterally spreading tumors on still images. Multicenter trials should be conducted to confirm the usefulness of autofluorescence imaging in detecting laterally spreading colorectal tumors.
\end{abstract}

\section{Introduction}

Colorectal carcinoma is one of the most common cancers worldwide, and its prevalence is steadily increasing in Japan [1]. Colonoscopy is considered the gold standard for the detection of neoplastic lesions at risk of progression to colorectal carcinoma. However, according to the results of back-to-back colonoscopies by Rex et al., the miss rate for adenomas $\geq 1 \mathrm{~cm}$ was $6 \%$ [2]. Laterally spreading tumors (LSTs) constitute a subset of nonpolypoidal colonic lesions, which are characterized by lateral and circumferential extension along the colonic wall rather than vertical growth [3]. LSTs are further classified based on their macroscopic appearance. The granular type LST (LST-G) is defined by the presence of aggregates of even or uneven nodules on the surface, whereas the non-granular-type LST (LST-NG) has a smooth surface lacking the granulonodular formations $[4,5]$. Owing to the flat shape of LSTs, the miss rate for these tumors might be higher than the $6 \%$ reported by Rex et al. In addition, LSTs, particularly the NG type, have a higher potential for malignancy; nearly $30 \%$ of LST-NGs are associated with lymph follicular or multifocal submucosal invasion [6]. A reduction in the miss rate for LST-NG could therefore contribute to colorectal cancer prevention. Emerging data suggest that the use of image-enhanced endoscopy (IEE) such as autofluorescence imaging (AFI) and narrow-band imaging (NBI) may lead to improvements in polyp detection rates, although this notion remains controversial [7-15]. In our experience, we have encountered many LST-NG lesions that were better visualized by IEE than by white-light imaging (WL). The aim of this study was to evaluate the quality of visualization of LST-NG provided by IEE.

\section{Methods}

From September 2009 to April 2011, consecutive patients with LST-NG lesions resected by endoscopic submucosal 
TABLE 1: Characteristics of lesions.

\begin{tabular}{lc}
\hline Number of lesions & 47 \\
Number of patients & 45 \\
Sex & \\
$\quad$ Male & 31 \\
$\quad$ Female & 24 \\
Age (years) & \\
$\quad$ Median & 69 \\
$\quad$ Range & $50-80$ \\
Tumor size $(\mathrm{mm})$ & \\
$\quad$ Median & 30 \\
$\quad$ Range & $20-60$ \\
Tumor location & \\
$\quad$ Cecum & 1 \\
Colon & 39 \\
Rectum & 7 \\
Histopathology & \\
Adenoma & \\
m-ca & 5 \\
sm superficial $(\mathrm{sm} 1 *)$ & 24 \\
sm deep $(\operatorname{sm} 2-3)$ & 11 \\
\hline *sm1 : sm $<1000 \mu m$. & 7 \\
\hline
\end{tabular}

dissection (ESD) in our institution were included in this study. The inclusion criteria for performing ESD on LSTNGs were as follows: (1) evidence of a noninvasive pattern [15-17] and (2) lesions larger than $20 \mathrm{~mm}$ that were difficult to resect enbloc by using conventional EMR [18]. First, endoscopic examinations were performed using the white-light mode of the AFI videoendoscope system to identify LST-NG lesions, once lesions were detected, the colonoscopist conducted AFI and NBI examinations by switching first to the AFI mode followed by the NBI mode, and finally lesions were examined by chromoendoscopy (CE) using the white-light mode. AFI colonoscopes (EVIS CF-FH260AZI; Olympus Medical Systems, Tokyo, Japan), light sources (EVIS CLV260SL; Olympus Medical Systems), and video processors (EVISLUCERA CV-260SL; Olympus Medical Systems) were used in this study. The AFI videoendoscope system is a novel illumination method that produces real-time pseudocolor images. Neoplastic lesions involve a thickening of the mucosal layer and increased hemoglobin so such lesions emit weaker autofluorescence compared to nonneoplastic lesions; therefore nonneoplastic lesion appears green, while neoplastic lesion has a magenta image [7]. The AFI system allowed for immediate switching from WL to AFI and NBI with a button on the control head of the endoscope. CE was performed using $0.4 \%$ indigo carmine. Images of the lesions from WL, NBI, AFI, and CE without magnification were captured and electronically archived in the electronic medical records of our hospital. The images were selected by an experienced endoscopist blinded to this study. The WL, NBI, AFI, and CE images for each lesion were downloaded. The images of all the lesions were randomly arranged, and a Microsoft PowerPoint presentation was created. These images did not contain any information to identify the

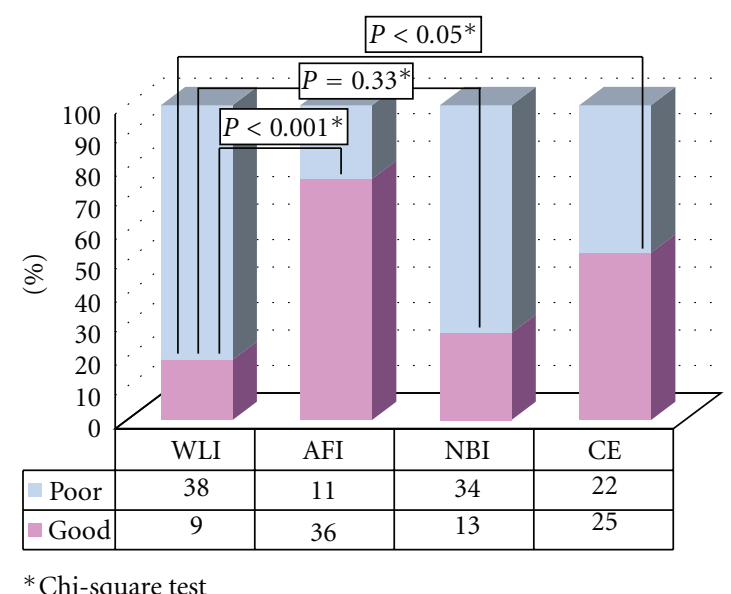

Figure 1: Visualization of LST-NG in group A.

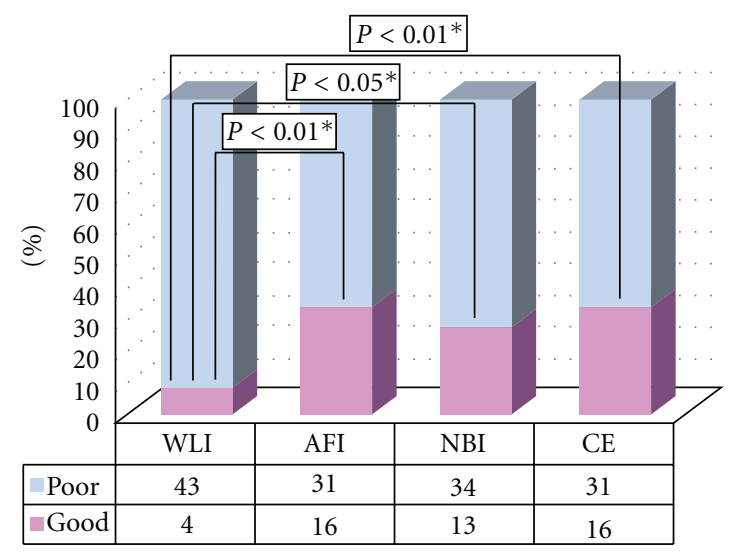

* Fisher's exact test

FIGURE 2: Visualization of LST-NG in group B.

patient or the lesion. The PowerPoint presentations were sent to the respective raters for their independent evaluation. The images were assessed by 2 groups of endoscopists (A and B). Group A comprised 2 physicians with no previous experience in IEE, and group B comprised 2 endoscopists, each of whom had analyzed over 100 cases by using IEE. Each endoscopic image was assessed and given a global rating for visualization based on the ability to detect the lesion and the clarity of the tumor margins. The images were rated by the endoscopists on a 5 -point scale as follows: 5 , very well visualized; 4 , well visualized; 3 , moderately well visualized; 2 , poorly visualized; 1 , very poorly visualized. The ratings of the images were analyzed separately for groups A and B. For each group of raters, the quality of visualization of lesions that received a score of 4 or more from both the raters was classified as "good". The quality of visualization of lesions with a score below 4 was classified as "poor."

\section{Statistical Analysis}

Statistical analysis was performed using SPSS for Windows (SPSS, Release 6.0; SPSS Inc., Chicago, Ill, USA, 1993). Statistical significance was defined as a $P$-value less than 0.05 . 


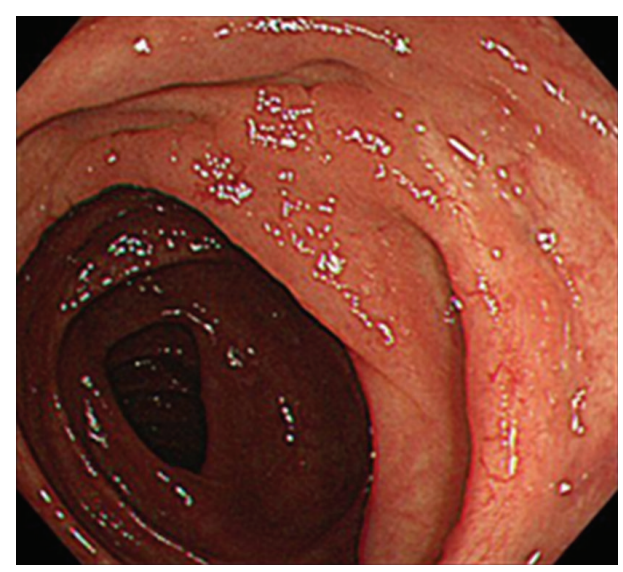

(a) WL image

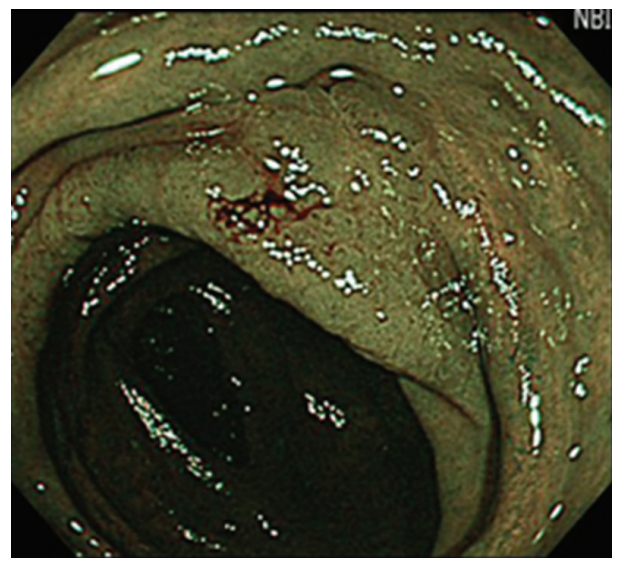

(c) NBI image

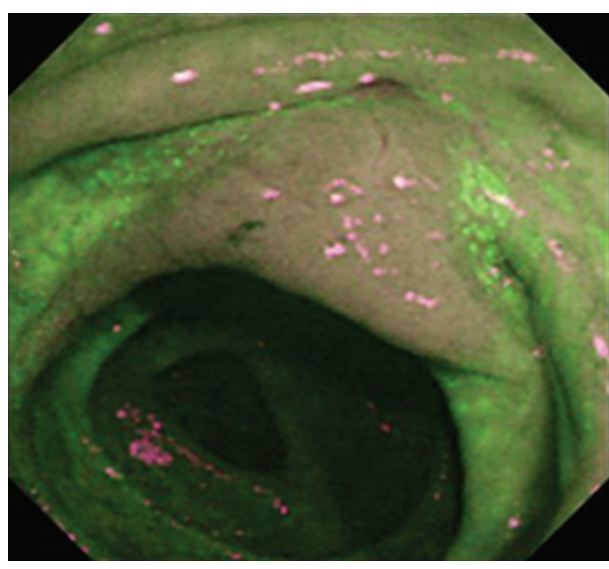

(b) AFI image

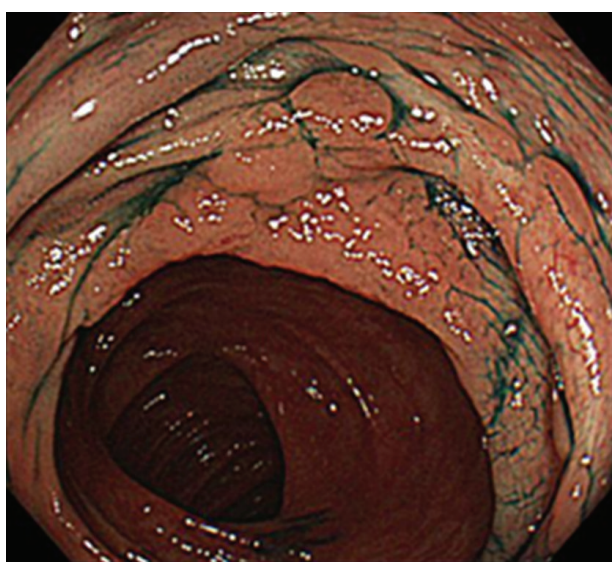

(d) chromoendoscopy with indigo carmine

Figure 3: LST-NG lesions categorized as "wellvisualized” using AFI. Location: Transverse colon. Size of the lesion: $45 \mathrm{~mm}$. Macroscopic type: IIa (LST-NG). Pathological findings: well-differentiated adenocarcinoma, low-grade atypia, Pm.

\section{Results}

In all, 49 LST-NG lesions in 47 patients were included in this study. Two patients with lesions were excluded from this study, because the lesions were not observed in the same field in each of the 4 modalities. Finally, a total of 47 LST-NG lesions in 45 patients were evaluated (Table 1). Of the 47 lesions analyzed in group $A$, the quality of visualization was categorized as "good" for 6 lesions using AFI, 13 using NBI, and 25 using CE. AFI (36/47) provided significantly better visualization than WL $(9 / 47)(P<0.001)$. Similarly, there was a significant difference between the quality of visualization using CE (25/47) and WLI (9/47) $(P<0.05)$. There was no significant difference, however, between WLI (9/47) and NBI (25/47) (Figure 1). Regarding AFI visualization, there was no significant difference in the macroscopic subtype, tumor location, or underlying histology between well-visualized and poorly visualized lesions, but well-visualized lesions were larger than the poorly visualized lesions (Table 2).

In group B, the quality of visualization was assessed as "good" for 4 lesions by using WLI, 16 lesions by using AFI, 13 lesions by using NBI, and 16 lesions by using CE. There was a significant difference in the frequency of well-visualized lesions between AFI $(16 / 47)$ and WLI $(4 / 47)(P<0.001)$. Similarly, a significant difference in visualization quality was observed between CE $(16 / 47)$ and WLI $(16 / 47)(P<0.01)$ and between NBI $(13 / 47)$ and WLI $(4 / 47)(P<0.05)$ in group B (Figure 2). Regarding AFI, there was no significant difference in the macroscopic subtype, tumor location, or underlying histology between well-visualized and poorly visualized lesions. Well-visualized lesions were larger than the poorly visualized ones (Table 3 ).

\section{Discussion}

Based on the results of our study, AFI provides good-quality visualization of LST-NG lesions, not only for experienced endoscopists but for less-experienced endoscopists as well. The utility of AFI for the detection of colorectal tumors still remains controversial, with studies reporting mixed results $[7-9,15,19]$. In this study, 2 LST-NG lesions were determined to be well visualized by 4 endoscopists (Figures 3 and 4.). As Figures 1 and 2 show, we observed LSTNG lesions that were better visualized using AFI than the other methods. The relationship between visualization and 


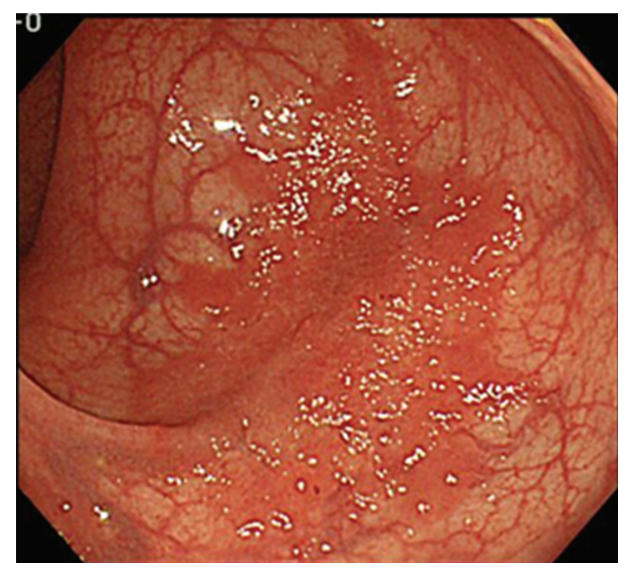

(a) WL image

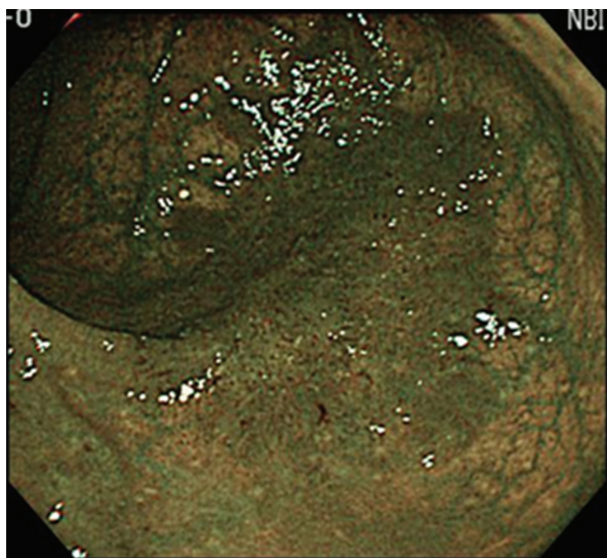

(c) NBI image

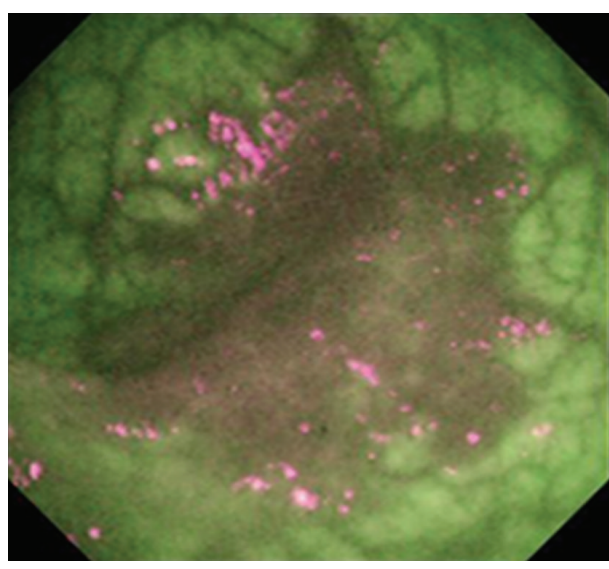

(b) AFI image

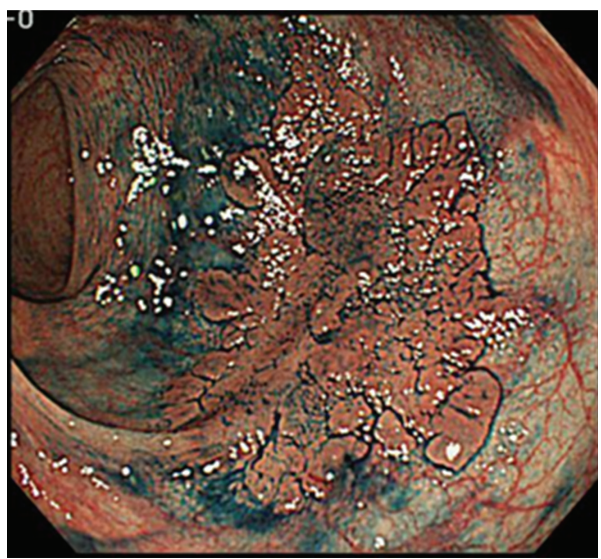

(d) Chromoendoscopy with indigo carmine

FIGURE 4: LST-NG lesions categorized as “wellvisualized” by using AFI. Location: lower rectum. Size of the lesion: 45 mm. Macroscopic type: IIa (LST-NG). Pathological findings: well and moderately differentiated adenocarcinoma, pSM (350 um).

detection is uncertain. However, better visualization may enable improved detection of LST lesions, especially those of the NG type, which have been shown to be difficult to detect with CE [4]. It is particularly important to improve the detection rate of LST-NGs, because they are more likely to harbor malignancy; nearly $30 \%$ of LSTs of the NG type involve lymph follicular or multifocal submucosal invasion [6]. Though LST-NG lesions are less prevalent than polypoidal lesions, their greater malignant potential necessitates reliable detection methods. This study suggests that AFI is superior to WLI for the detection of LST-NG lesions at least on still images. In the present study, there was no significant difference in the quality of visualization of LST-NGs between WLI and NBI for the less-experienced endoscopists.

We also evaluated LST-G lesions in the same fashion as for the LST-NGs. As shown in Figures 5 and 6, AFI also provided good-quality visualization of LST-G lesions for the less-experienced endoscopists, despite the lack of a significant difference in visualization quality between WLI and AFI for the experienced endoscopists. This result indicates that an advantage of AFI might be that it simplifies observations for less-experienced endoscopists. We also compared the backgrounds of the LST-NG lesions between those with good
TABLE 2: Backgrounds of the LST-NG lesion evaluated by AFI in group A.

\begin{tabular}{lccc}
\hline & \multicolumn{2}{c}{ Quality of visualization } & \\
& Good & Poor & $P$ \\
\hline Macroscopic type & & & \\
$\quad$ Flat elevated & 32 & 9 & $0.30^{*}$ \\
$\quad$ Flat or flat depressed & 4 & 2 & \\
Lesion size (mm) & & & \\
$\quad$ Median & 25 & 35 & $<0.05^{* *}$ \\
$\quad$ Range & $20-50$ & $20-60$ & \\
Location & & & $0.34^{*}$ \\
$\quad$ Rectum & 6 & 1 & \\
$\quad$ Cecum or colon & 30 & 10 & $0.30^{*}$ \\
Pathological finding & & & \\
$\quad$ Adenoma & 4 & 2 & \\
Adenocarcinoma & 32 & 9 & \\
\hline
\end{tabular}

${ }^{*}$ Fisher's exact test.

***Mann-Whitney test.

versus poor visualization quality by using AFI. There were no significant differences between lesions that had good versus poor visualization quality with respect to macroscopic 
TABLE 3: Characterization of LST-NG lesions by AFI in group B.

\begin{tabular}{lccc}
\hline & \multicolumn{2}{c}{ Quality of visualization } & \\
& Good & Poor & $P$ \\
\hline Macroscopic type & & 25 & \\
$\quad$ Flat elevated & 16 & 6 & $0.07^{*}$ \\
$\quad$ Flat or flat depressed & 0 & & \\
Lesion size (mm) & & 30 & $<0.05^{* *}$ \\
$\quad$ Median & 25 & $20-60$ & \\
$\quad$ Range & $20-45$ & & \\
Location & & 5 & $0.32^{*}$ \\
$\quad$ Rectum & 2 & 26 & \\
$\quad$ Cecum or colon & 14 & & $0.08^{*}$ \\
Pathological finding & & 29 & \\
$\quad$ Adenoma & 4 & & \\
Adenocarcinoma & 12 & &
\end{tabular}

* Fisher's exact test.

*** Mann-Whitney test.

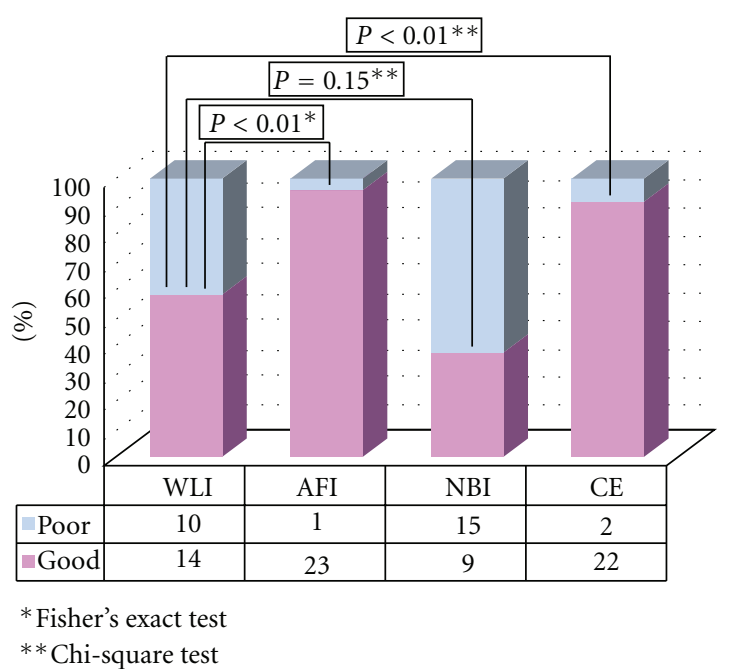

FIgURE 5: Visualization of LST-G in group A.

type, location, or pathological findings. However, the wellvisualized lesions were larger than the poorly visualized lesions in groups A and B. To obtain a whole image of a large lesion, it is necessary to maintain sufficient distance between the tip of the scope and the lesion, which may affect the visibility of the lesion.

This study had several limitations. Only still images were evaluated, and it is uncertain if these findings can be applied to real-time video endoscopy. A relatively small sample precludes any multivariate analysis. Larger studies are needed to define the factors influencing the quality of visualization.

\section{Conclusion}

AFI provides good-quality visualization of LST-NG lesions on still images. However, to confirm the detectability of LST-NG lesions by using AFI, multicenter trials should be performed.

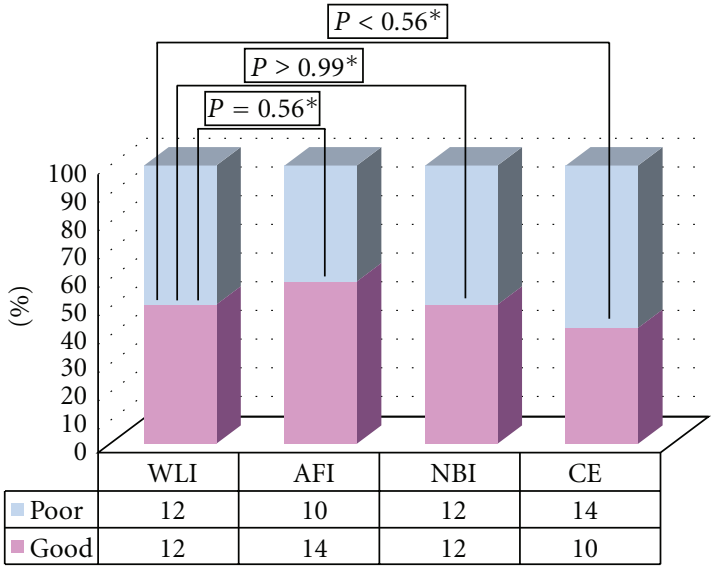

*Chi-square test

Figure 6: Visualization of LST-G in group B.

\section{Conflict of Interests}

All authors have no conflict of interests or financial ties to disclose.

\section{References}

[1] T. Matsuda, T. Marugame, K. Kamo et al., "Cancer incidence and incidence rates in Japan in 2002: based on data from 11 population-based cancer registries," Japanese Journal of Clinical Oncology, vol. 38, no. 9, pp. 641-648, 2008.

[2] D. K. Rex, C. S. Cutler, G. T. Lemmel et al., "Colonoscopic miss rates of adenomas determined by back-to-back colonoscopies," Gastroenterology, vol. 112, no. 1, pp. 24-28, 1997.

[3] S. Kudo, "Endoscopic mucosal resection of flat and depressed types of early colorectal cancer," Endoscopy, vol. 25, no. 7, pp. 455-461, 1993.

[4] S. E. Kudo, H. Kashida, T. Tamura et al., "Colonoscopic diagnosis and management of nonpolypoid early colorectal cancer," World Journal of Surgery, vol. 24, no. 9, pp. 1081-1090, 2000.

[5] S. Kudo, R. Shimoda, and H. Kashida, "Laterally spreading tumor of colon: definition and history (in Japanese with English abstract)," Stomach Intestine, vol. 40, pp. 1721-1725, 2005.

[6] T. Uraoka, Y. Saito, T. Matsuda et al., "Endoscopic indications for endoscopic mucosal resection of laterally spreading tumours in the colorectum," Gut, vol. 55, no. 11, pp. 15921597, 2006.

[7] T. Matsuda, Y. Saito, K.-I. Fu et al., "Does autofluorescence imaging videoendoscopy system improve the colonoscopic polyp detection rate?- - a pilot study," The American Journal of Gastroenterology, vol. 103, no. 8, pp. 1926-1932, 2008.

[8] Y. Takeuchi, T. Inoue, N. Hanaoka et al., "Autofluorescence imaging with a transparent hood for detection of colorectal neoplasms: a prospective, randomized trial," Gastrointestinal Endoscopy, vol. 72, no. 5, pp. 1006-1013, 2010.

[9] T. Kuiper, F. J. C. van den Broek, A. H. Naber et al., "Endoscopic trimodal imaging detects colonic neoplasia as well as standard video endoscopy," Gastroenterology, vol. 140, no. 7, pp. 1887-1894, 2011. 
[10] T. Uraoka, Y. Saito, T. Matsuda et al., "Detectability of colorectal neoplastic lesions using a narrow-band imaging system: a pilot study," Journal of Gastroenterology and Hepatology, vol. 23, no. 12, pp. 1810-1815, 2008.

[11] A. Rastogi, D. S. Early, N. Gupta et al., "Randomized, controlled trial of standard-definition white-light, high-definition white-light, and narrow-band imaging colonoscopy for the detection of colon polyps and prediction of polyp histology," Gastrointestinal Endoscopy, vol. 74, no. 3, pp. 593-602, 2011.

[12] T. Inoue, M. Murano, N. Murano et al., "Comparative study of conventional colonoscopy and pan-colonic narrow-band imaging system in the detection of neoplastic colonic polyps: a randomized, controlled trial," Journal of Gastroenterology, vol. 43, no. 1, pp. 45-50, 2008.

[13] A. Rastogi, A. Bansal, S. Wani et al., "Narrow-band imaging colonoscopy-a pilot feasibility study for the detection of polyps and correlation of surface patterns with polyp histologic diagnosis," Gastrointestinal Endoscopy, vol. 67, no. 2, pp. 280-286, 2008.

[14] A. Adler, H. Pohl, I. S. Papanikolaou et al., "A prospective randomised study on narrow-band imaging versus conventional colonoscopy for adenoma detection: does narrow-band imaging induce a learning effect?" Gut, vol. 57, no. 1, pp. 5964, 2008.

[15] H. Suzuki, Y. Saito, T. Matsuda, T. Nakajima, and T. Kikuchi, "Prospective case study on characterization of colorectal adenomas comparing AFI with NBI," Diagnostic and Therapeutic Endoscopy, vol. 2011, Article ID 963618, 6 pages, 2011.

[16] T. Fujii, R. T. Hasegawa, Y. Saitoh et al., "Chromoscopy during colonoscopy," Endoscopy, vol. 33, no. 12, pp. 1036-1041, 2001.

[17] Y. Saito, F. Emura, T. Matsuda et al., "Invasive pattern is an indication for surgical treatment," Gut, 2004, http:/gut .bmjjournals.com/cgi/eletters/53/2/284.

[18] T. Matsuda, T. Fujii, Y. Saito et al., "Efficacy of the invasive/ non-invasive pattern by magnifying chromoendoscopy to estimate the depth of invasion of early colorectal neoplasms," The American Journal of Gastroenterology, vol. 103, no. 11, pp. 2700-2706, 2008.

[19] Y. Saito, T. Uraoka, Y. Yamaguchi et al., "A prospective, multicenter study of 1111 colorectal endoscopic submucosal dissections (with video)," Gastrointestinal Endoscopy, vol. 72, no. 6, pp. 1217-1225, 2010. 


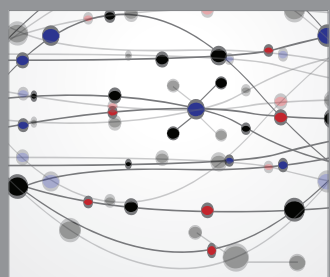

The Scientific World Journal
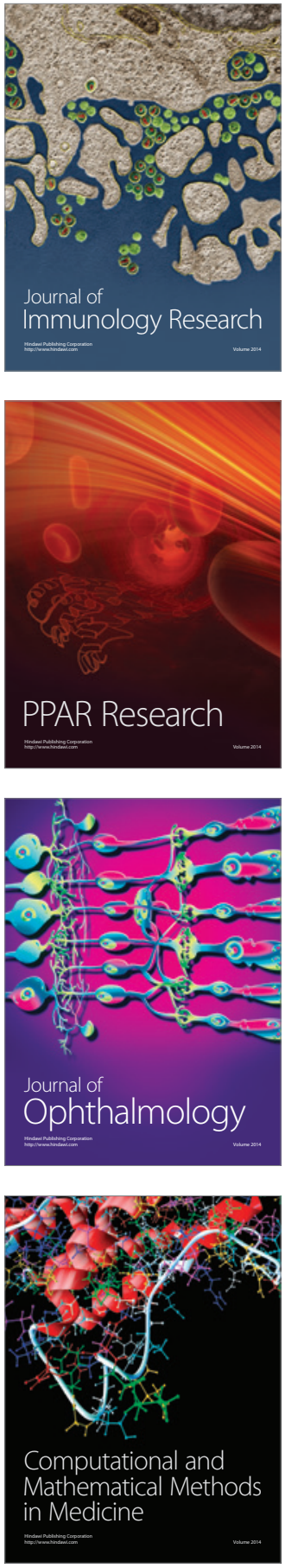

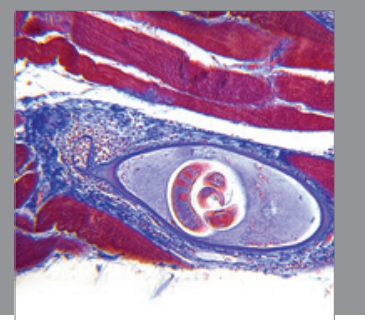

Gastroenterology

Research and Practice
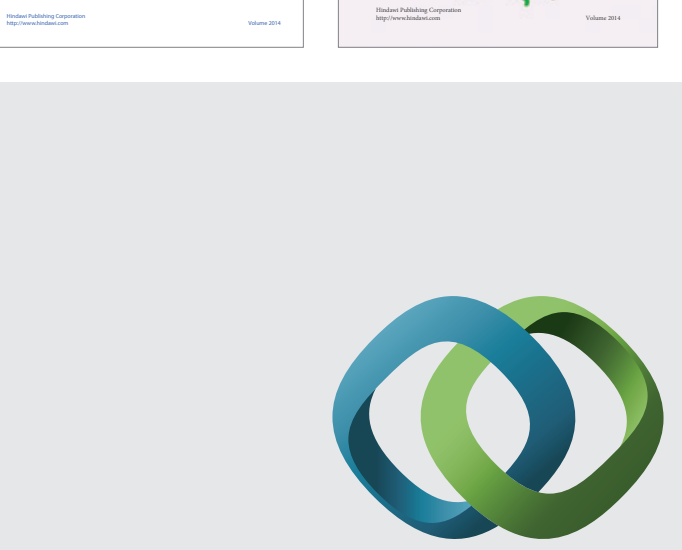

\section{Hindawi}

Submit your manuscripts at

http://www.hindawi.com
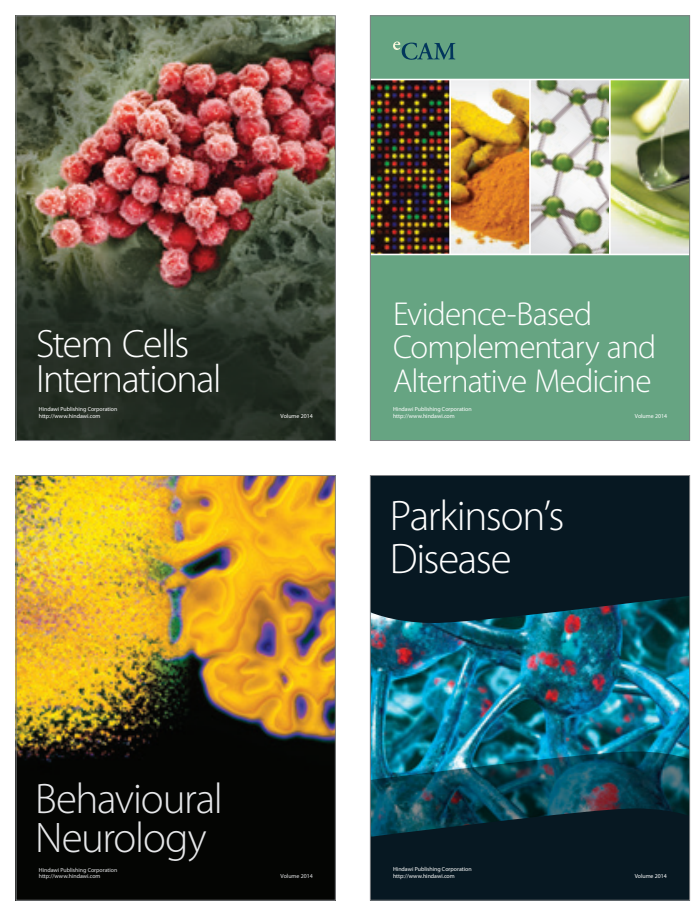

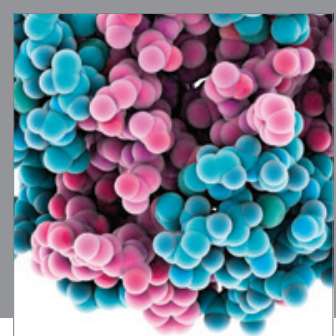

Journal of
Diabetes Research

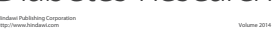

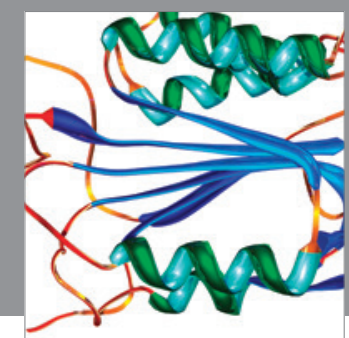

Disease Markers
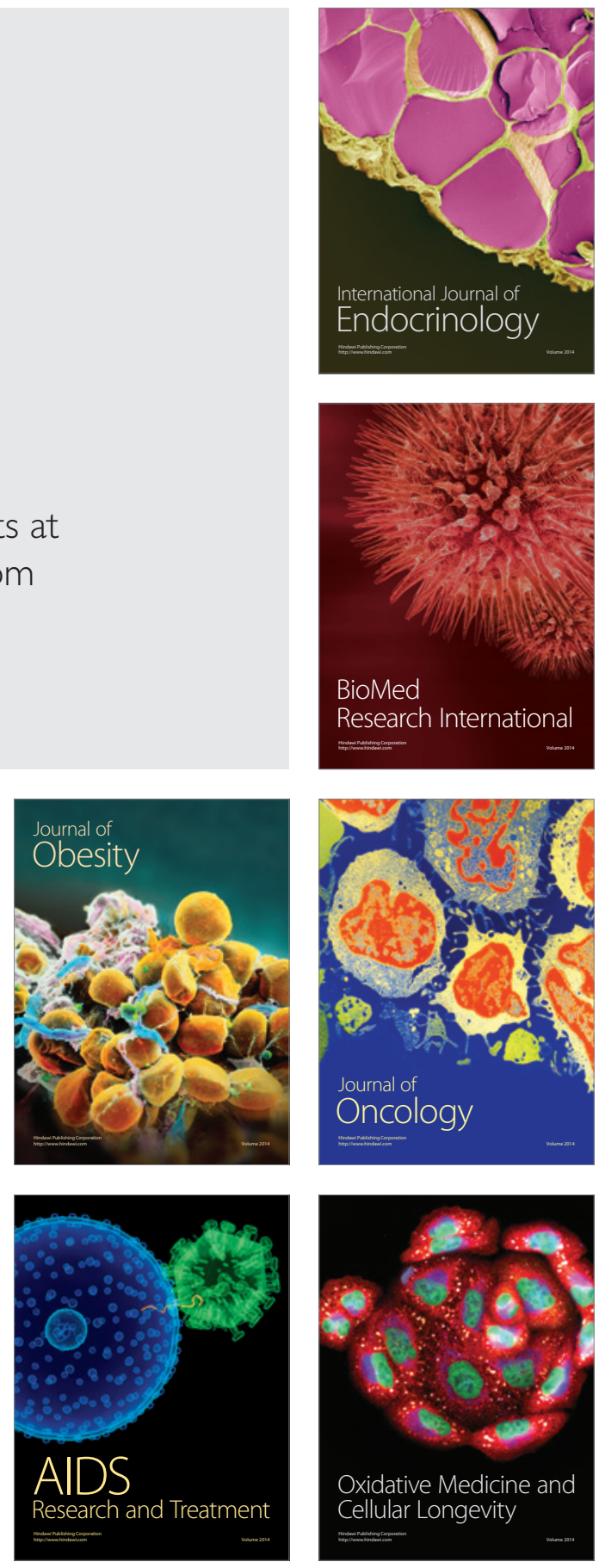